\title{
Foreign Universities in India- Ethical Issues in New Scenario
}

\author{
V. Anoop Kumar ${ }^{1}$ Dr. R. Ganesan ${ }^{2}$ \\ ${ }^{1}$ (Research Scholar, Bharathiar University, Coimbatore. Asst. Professor, Dept. of Management Studies, P.A. \\ College of Engineering and Technology, Coimbatore, India) \\ ${ }^{2}$ (Principal, Sri Venkateshwara College of Computer Applications and Management, Coimbatore, India)
}

\begin{abstract}
The Government of India has decided to permit foreign Universities to India without taking much precautions and studies in this area. The Government's move allowing the entry of foreign Universities in the country has always been a contentious issue since it was proposed. Moreover, the argument about the consequences of such an initiative has always brought out the downsides more than the foreseen positive effects. Even though there are so many positive dimensions to the decision, we should consider the matter carefully to avoid any kind of invasion to our cultural as well as educational heritage which are appreciated internationally and the reality foreigners are utilizing the benefits of the same as much.

This paper provides an overview of trends and issues, explores their ethical dimensions, and tries to identify relevant strategies to prepare India to deal appropriately with these concerns of the intervention of the foreign Universities in India. The study treats both issues in foreign Universities in India and the ethical aspects of the intervention in the Indian diversity.

The foreign Universities come here for nothing but to make money, so there is no doubt they consider it as a business and take all bossiness tricks to education field. The fee structure that they are going to introduce may not be affordable even to the high class group of our country, and this will create more gap between the poor and lords, the impact of this may not be solved in future too.

The hidden agenda of foreign Universities and their policies cannot be considered much; we cannot chalk out their hidden agendas. The people who came here for business later became the rulers of our country is the history. The charity works of some organizations and related hidden agendas are also a hot discussion right now. So, we should be careful to the hidden agendas of each course. Hence the necessity of serious considerations of the ethical issues involved, before taking a final decision.
\end{abstract}

Key words: Ethical aspects, Heritage, intervention, UGC, Repatriate

\section{Introduction}

The Government of India has decided to permit foreign Universities to India without taking much precautions and studies in this area. . The Government's move allowing the entry of foreign Universities in the country has always been a contentious issue since it was proposed. Moreover, the argument about the consequences of such an initiative has always brought out the downsides more than the foreseen positive effects even though there are so many positive dimensions to the decision, we should consider the matter carefully to avoid any kind of invasion to our cultural as well as educational heritage which are appreciated internationally and the reality that foreigners are utilizing the benefits of the same as much.

Human beings have an innate ethical sense that urges them to make predictable choices. Although most people believe that their actions are guided by logic and reason, reason often acts only as a mechanism to justify these choices. Language allows people to construct sophisticated rationales which support what are often emotionally driven decisions.

Our University system simply is not producing well- educated graduates to meet the needs of Indian companies today. The major problem remains that our national education policy in the past has remained out of step with the time. Whereas countries in the Middle-East and China are going out of their way to woo foreign Universities to set up campuses in their countries, India turned away many academic suitors who have came calling in recent years.

This paper provides an overview of trends and issues, explores their ethical dimensions, and tries to identify relevant strategies to prepare India to deal appropriately with these concerns of the intervention of the foreign Universities in India. The study treats both issues involved in foreign Universities in India and the ethical aspects of the intervention in the Indian diversity.

\section{Statement of the Problem}

The move to permit entry of foreign Universities and educational institutions into India has become a contentious issue. Even as the Central Government is on a reform-spree amidst huge opposition, the proposed Foreign Educational Institutions (Regulation of Entry and Operations) Bill 2010 too comes into focus. With the Central Government unsure of getting the Foreign Educational Institutions (Regulation of Entry and Operations) 
Bill, 2010, through the Lok Sabha, the Human Resource Development Ministry is now trying to allow "backdoor" entry to foreign institutions.

The Ministry has asked the University Grants Commission (UGC) to identify possibilities within the existing laws of regulating and allowing the foreign educational institutions. The recent revelations of Minister of State for Higher Education Mr.Shashi Tharoor are enough indication to this line.

The two possible ways of going about it are allowing these institutions to enter as 'Deemed Universities' under Section 3 of the University Grants Commission Act, 1956, or as private Universities under the State laws.

At the same time, the UGC is also drafting regulations on twinning programmes and joint degree programmes between the foreign and Indian educational institutions.

The Foreign Universities Bill is puzzling for two reasons: One, it proposes that a business operating in India can be exempted from the letter and spirit of the prevailing laws of the land on the grounds that the owner is foreign ; and two, this proposed exemption from reservations comes from a Government that is otherwise very, very clear about its position -- on the inclusion of backward classes and economically-weaker sections into educational institutions.

The same Government, not too long ago, demonstrated, in words and deeds, its passionate belief that everyone should have a reasonable shot at getting the best possible education -- it made haste to enable, and with an iron hand, even supervised implementation of a speedy inclusion of other backward classes (OBCs), in addition to that of scheduled castes/scheduled tribes (SCs/STs), into all institutions of higher learning.

\section{Factfile}

$\checkmark$ Foreign education institutions have increased from 144 (2000) to 631 (2010), and goes on increasing exponentially.

$\checkmark$ The maximum number were from the UK (158), followed by Canada (80) and the US (44)

$\checkmark$ Of the 60 foreign education providers, who have programme collaboration with local institutions, only 25 local institutions were affiliated to Indian Universities or approved by regulatory bodies

$\checkmark$ Only 32 of the 49 foreign institutions operating under twinning arrangements have approval or affiliation (Source: Association of Indian Universities)

\section{Foreign Educational Institutions (Regulation of Entry and Operation) Bill}

It aims to regulate the entry and operation of foreign educational institutions seeking to impart higher education. Every foreign educational institution intending to operate in India has to be notified as a foreign educational provider by the central Government on the recommendation of the registrar (secretary of the University Grants Commission). The bill was introduced in the Lok Sabha in May 2010, and then referred to a parliamentary standing committee. The committee gave its report in May 2011.

The foreign Universities bill was approved by the Union Cabinet in March (2010) and was introduced in the Lok Sabha on May 3, 2010 and still remain in uncertainty.

The bill, once passed, has the potential to create the same impact on India's higher education sector as the economic liberalization and deregulation in the $90 \mathrm{~s} \mathrm{had} \mathrm{on} \mathrm{India's} \mathrm{industrial} \mathrm{sector.} \mathrm{And} \mathrm{since} \mathrm{demand} \mathrm{is} \mathrm{going}$ to increase exponentially, because India has a young population, we need to increase the institution of the supply. And all stakeholders - industry, private sector, foreign and public partnership should have a chance to participate in the system.

The bill is unclear whether reservation of seats for OBC and SC/ST students would be an eligibility criterion for the foreign educational institutions to be notified as Foreign Education Providers (FEP).

The FEPs would be treated as Indian private Universities and allowed to set their own fee and would be exempted from reservations. Also, one of the concerns expressed in the monograph is the imposition of the condition that no repatriation of profits will be allowed might act as a deterrent for the foreign Universities to enter India. Without a possibility of taking back its invested capital, a foreign institution might simply choose to not enter the Indian education sector. Also, foreign Universities are collaborating for research, but are hesitant to set up campuses in India because the Indian Government regulations restrict aspects of administration including fees, salary and research grant.

\section{Major Ethical Concerns}

More than $35 \%$ of Indian population is illiterate. Has our Government made any serious effort to resolve this other than granting permissions to a cohort of private schools which are well very on track to make schools as commercial institutions. Introducing foreign Universities is never going to put an end to solve this crisis. In terms of infrastructure, many Indian Universities can boast of a world class facility. At the moment, it seems that foreign Universities will target only the huge undergraduate degree market, as introducing postgraduate courses here could endanger the enrolment of Indians on foreign campuses. The Government should hence permit them on condition that they begin with postgraduate/doctoral education for the first 10 
years with their own existing faculty. While this will be a litmus test of the true intentions of the foreign Universities, the time period will help level the playing field for Indian institutions to take on foreign competition.

Since the students they produce would eye a more dynamic career in the global platform rather than being a faculty in any of the Indian Universities which would pay a relatively lesser salary than others, this will leave the Indian education system prone to a catastrophic dysfunction in the coming days.

The persisting faculty crisis in Indian higher education presents a bleak picture. On May 5 last year (2012), the Lok Sabha was informed that 34 per cent of the 11,085 teaching positions across 22 Universities in India are lying vacant. Fallout of permitting foreign Universities is the likely flight of teachers from the Indian institutions, compounding the existing shortage of qualified faculty. The Indian Universities will not be able to retain their teachers as with their drastically lower fee structures, they cannot match the pay packets of the foreign Universities. The paucity of qualified faculty is felt even more in professional and technical institutions. With the engineering students in India increasing every day, institutions are facing a faculty shortage to the extent of 67 per cent all over the country. Even in premier institutes like the IITs, faculty shortage is an issue of serious concern. Foreign universities can only add to this.

Here we have to quote Mr. Manmohan Singh's words in 2011 "Our University system is, in many parts, in a state of disrepair...In almost half the districts in the country, higher education enrollments are abysmally low, almost two-third of our Universities and 90 per cent of our colleges are rated as below average on quality parameters." What Mr. Singh feels is 200 percent true but letting in foreign Universities in India is going to end this? In fact, it would add more insult to the injury and will soon transform higher education an unattainable dream for below poverty line, lower class and lower middle class people.

Another area of discussion is that with emphasis only on engineering studies, introduced by the foreign Universities, there is neglect of basic sciences and humanities-- an important area of our educational system. As a democratic identity, India needs sufficient importance to the humanities sector. The emphasis given to basic education and humanities will be ignored and which will make a long period impact to the Indian systems as we need to give priorities to many of our basic issues.

Some other points to be discussed in these issues are the economic side of the foreign education. Only high profile economic group can afford the expenses incurred in these Universities. Also the competency of the students may be varied.

The issues developed in the private medical college admission and related issues may be discussed in this context. The lack of students to study in our self financing colleges is also need to be discussed.

In India, these initiatives end up like a drop in the ocean. With this, huge investments for setting up such institutions will be a major deterrent. Foreign Universities and colleges are facing cut backs in Government grants and assistance on account of the recent ongoing recession. So, they may not have funds in near future to take advantage of this permission. This might lead them to market their current facilities in countries like India and let international students pay.

In addition, there is an inherent risk of only B-grade international Universities and colleges setting up base here. The objective of providing quality education may be defeated. The bill also has a major flaw as it sets no limits on the fee to be charged. That leaves the door open for exploitation in the name of "foreign" University/college.

\section{Some Other Related Ethical Issues}

1. Comparison between the value of Indian and foreign University certificate. We have a very much appreciated system for education both technical and non technical. When the foreign Universities enter to our current system, the people may develop a comparison between the Indian and foreign University education, which will create some ethical issues to the Indian educational system. We have an issue like this among the students from English medium and mother tongue medium students, but really the output are not much varied.

2. Invasion to the Indian cultural as well as historical heritage. The foreign Universities have their own syllabus and methodology for imparting education. This will definitely according to the policy and practices in their country. The westernization and its impacts in Indian society is already in a hot discussion matter and not much appreciated or accepted by our society. We are not ready to permit any kind of invasions to our long heritage and culture which is still focused by the foreigners.

3. Quality of the imparted education. The foreign Universities may give more importance to the certification of the students than the training and education. Most of them may give the other part to some other Indian bodies or institutions which will also dilute the quality of students, then the much highlighted benefit of entering foreign Universities in to India. 
4. From social point of view. No University comes here to give free education or reservations to any minority or under privileged sections of our country. Basically these reservations and special considerations help us to develop a balance among the people, groups and communities.

5. From economic point of view. The foreign Universities come here for nothing but to make money. So, there is no doubt they consider it as a business and take all bossiness tricks to education field. The fee structure introducing may not be affordable even to the high class group of our country, and this will create more gap between the poor and lords The impact of this may not be solved in future too.

6. From Students perspective. The move to open up domestic education has come across strong opposition from various academicians, authorities and most importantly the students, for whom the initiative has been taken. How students feel about having foreign Universities in India is the question of prime importance.

Recently, a group of under graduate and postgraduate students from a college in south India were asked about the Foreign Universities Bill. The students shared their thoughts and had a heated discussion on the issue. Most of students asked about the move did not support the idea of foreign Universities entering the country and tagged it as an 'anti national' move. The students came to the conclusion after wrangling over the negative aspects of the government's new move.

The students strongly opposed the outsourcing of education and believed that the entry of foreign institutes will hinder the growth of Indian education. In their view, instead of opening up the gates for collaboration, the Government should find out other ways to improve the domestic education. They felt that it (Foreign Universities Bill) would give foreigners a chance to dominate our country again and would lead to the problems of inferiority complex and cultural differences in the country.

It was pointed out that the entry of foreign institutes will negatively influence the Indian colleges and Universities. Allured by the foreign Universities' set-ups in the country, no student would really value the domestic institutes and therefore Indian education will eventually loose its sheen.

In their strong opposition to the bill, the students firmly said that the Government should not sell our country in the name of improving the quality and standard of education. Instead of inviting the foreigners here, they said, we should learn and adopt the ways of the best Universities all over the world. The government was accused of being obsessed with foreign Universities/institutes and it was felt that we should carefully study the negative impacts on our domestic education and culture.

Amidst the skepticism toward the bill, the students forewarned the Government by saying that the move to open up the education sector will adversely affect our country and shared their fear that the Indian education and culture might fade away

\section{Conclusion}

The entrance of foreign Universities into India is a matter of major concern for all of us. The hidden agenda of foreign Universities and their policies may not be considered much. We cannot chalk out their hidden agendas. The people who came here for business later became the rulers of our country are the history. The charity works of some organizations and related hidden agendas are a hot discussion right now also. The pros and cons of the issue are to be evaluated with utmost care.

Again, we also need to be understood that Indian students do not pursue overseas education only for the purpose of education. Their intention may be to relocate to that country for better standards of life. This includes the overall quality of life, including employment and income opportunities that the developed countries offer. So irrespective of the scenario, the flow and outward movement to offshore educational facilities will continue unabated. The policy makers as well as the general public will have to take all precautionary measures to meet the challenges evoking by the decision. So we should consider these ethical sides also to take a final stand.

\section{Acknowledgements}

Remembering the facilitations provided by IIM-K, PSG Institute of Management, Coimbatore and Cochin University of Science and Technology authorities for their feedback, guidance and references. Above all, the blessings of the Almighty.

\section{References}

[1] Davy, J.A., Kincaid,J.F., Michelle,J.S. and Trawick,A.(2007),Fitzgerald, M.H., Phillips, P.A. and Yule, E., (2006), "The Research Ethics Review Processx and Ethics Review Narratives," Ethics and Behavior, Vol. 16, No. 4.

[2] Halbesleben, J.R.B., Buckley, M.R.and Sauer, N.D.,(2004), The Role of Pluralistic Ignorance in Perceptions of Unethical Behavior: An Investigation of Attorneys' and Students' Perceptions of Ethical Behavior, Ethics and Behavior, Vol. 14, No. 1.

[3] Hallowell, N., Lawton, J., and Gregory, S. (2005). Reflections on research: The realities of doing research in the social sciences. Buckingham: Open University Press. 
[4] HardingT.S.,Mayhew,J.M., Finelli,C.J. and Carpenter,D.D.(2007), The Theory of Planned Behavior as a Model of Academic Dishonesty in Engineering and Humanities Undergraduates, Ethics \& Behavior, Volume 17, Issue 3, 2007.

[5] ICMR (Indian Council of Medical Research) (1980), "Policy Statement on EthicalConsiderations Involved in Research on Human Subjects". New Delhi: ICMR.19

[6] ICMR (Indian Council of Medical Research) (1997), "Consultative Document onEthical Guidelines on Biomedical Research Involving Human Subjects".(Draft). New Delhi: ICMR.

[7] Jones, B. (2004). Perspectives on management research design and orientation:Quandries and choices. Electronic Journal of Bu siness Research Methods,2(2), 111-118.

[8] Kakabadse, N.K., Kakabadse, A., and Kouzmin, A. (2002). Ethical considerations in management research: A 'truth' seeker's guide. International Journal of Value-based Management, 15, 103-138.

[9] Rynes, S.L., Bartunek, J.M., and Daft, R.L. (2001). Across the great divide: Knowledge creatkion and transfer between practitioners and academics. Academy of Management Journal, 44 